\title{
Effectiveness of Vacuum Saturation Preconditioning Regime for Assessing Water Permeability of High Performance Concrete
}

\author{
Kai Yang and Changhui Yang \\ College of Materials Science and Engineering, Chongqing University \\ Muhammed Basheer \\ School of Civil Engineering, University of Leeds \\ Adrian Long and Sreejith Nanukuttan \\ School of Planning, Architecture and Civil Engineering, Queen's University Belfast \\ Yun Bai \\ Civil, Environmental and Geomatic Engineering, University College London
}

\begin{abstract}
Saturating high performance concrete (HPC) for assessing water permeability is a challenge. This paper reports a testing program established to determine the reliability and efficiency of an in situ preconditioning regime, the vacuum saturation, for the water permeability test. The vacuum saturation regime was examined through changing the parameters used and to justify if the field conditioning regime is able to yield similar results as in the laboratory, the results after vacuum saturation were statistically analysed and compared with that after incremental immersion. Its accuracy was further examined by additional experiments, whereas factors considered include different concrete mixes and different initial moisture conditions. The results suggest that the proposed method can eliminate the influence of moisture for different HPCs under the high initial moisture content. It is not effective, when the initial moisture content is low.
\end{abstract}

\section{INTRODUCTION}

The permeability of cover concrete is a key parameter to assess the durability of concrete structures (Basheer, 1991). To achieve non-destructive assessment of the permeability, numerous approaches have been attempted (Basheer, 2001; Bungey, Millard, \& Grantham, 2006; Figg, 1973; Parrott \& Hong, 1991; Torrent, 1992) that have been playing an important role in the quality control of structural concrete. However, almost none of them could effectively distinguish permeation characteristics of very low permeability concretes because of their low sensitivity to variations in permeability at these levels. Against this, the new water permeability tests were designed to ensure the differences between HPCs are clearly and reliably identified (Yang, Basheer, Bai, Magee, \& Long, 2014, 2015).

The in situ water permeability test is usually designed to be carried out under the saturation condition. Relatively fewer publications, however, concern the influence of moisture on water permeability tests compared with studies of air permeability tests. For the CLAM test, the area is saturated for $24 \mathrm{~h}$ by ponding before measurements (Adams, 1986), but this approach is not an effective way to achieve the saturated state for dense concrete (e.g., w/c <0.5) (Basheer, 1991). The results of Meletiou, Tia, and Bloomquist (1992) indicate that the effect of moisture variations on water permeability tests is nearly removed after applying vacuum saturation. Whiting (1981) also attempted to saturate concrete using the similar technique, as a part of the on site Rapid Chloride Permeability Test. It is noted that only normal concretes were examined in their studies. In the case of HPCs, very few works on the effect of moisture on in situ water permeability tests can be found. Furthermore, both studies do not give the detailed information about the effectiveness of vacuum saturation; and hence, the preconditioning procedures are not fully understood. Therefore, the in situ procedures for vacuum saturation still need to be developed for HPCs.

It is intended to establish a site saturation regime for the new water permeability test (Yang et al., 2015). In order to achieve this, two saturation regimes were selected, including vacuum saturation and incremental immersion. The vacuum saturation is 
regarded as a possible approach for the field use, whereas the incremental immersion is considered as the "reference" method, as the previous work (Yang et al., 2015) has shown that reliable water permeability results could be obtained after incremental immersion. That is, if the vacuum saturation can provide similar results as incremental immersion, it would be accepted as potential in situ precondition regimes.

\section{EXPERIMENTAL PROGRAMME}

\subsection{Materials and concrete mixes used}

Mix proportions of three HPCs selected were selected based on experiences gained from previous experimental work (Elahi, Basheer, Nanukuttan, \& Khan, 2010; Russell, 1999), details of which are given in Table 1. The cement used throughout was CEM-I conforming to BS-EN:197-1 (2000), and two supplementary cementitious materials (SCMs) were considered in this study, microsilica (MS) and pulverised fuel ash (PFA). The PFA conformed to BS-EN:450 (2005) was obtained from Kilroot Power station in Northern Ireland, UK, and MS conforming to BS-EN:13263-1 (2009) from Elkem in slurry form. A polycarboxylic acid-based superplasticiser was used to maintain consistent consistence.

Table 1. Concrete mix proportions and general properties.

\begin{tabular}{llll}
\hline \multicolumn{1}{c}{ Concrete } & PFA & PC & MF \\
\hline Water $\left(\mathrm{kg} / \mathrm{m}^{3}\right)$ & 145 & 145 & 145 \\
Portland cement $\left(\mathrm{kg} / \mathrm{m}^{3}\right)$ & 388 & 485 & 449 \\
Microsilica $\left(\mathrm{kg} / \mathrm{m}^{3}\right)$ & 0 & 0 & 36 \\
PFA $\left(\mathrm{kg} / \mathrm{m}^{3}\right)$ & 97 & 0 & 97 \\
Sand $\left(\mathrm{kg} / \mathrm{m}^{3}\right)$ & 668 & 689 & 652 \\
Coarse aggregate $\left(\mathrm{kg} / \mathrm{m}^{3}\right)$ & 1150 & 1150 & 1150 \\
Superplasticiser $(\%)$ & 1.4 & 1.3 & 1.5 \\
Air content $(\%)$ & 0.6 & 1.0 & 1.6 \\
Slump $(\mathrm{mm})$ & 220 & 225 & 240 \\
28-day compressive strength $(\mathrm{MPa})$ & 81.3 & 81.8 & 84.2 \\
56-day compressive strength $(\mathrm{MPa})$ & 90.7 & 87.3 & 94.6 \\
\hline
\end{tabular}

\subsection{Preparation of specimens}

For each concrete mix, $410 \mathrm{~mm} \times 100 \mathrm{~mm} \times 250 \mathrm{~mm}$ blocks were casted for water permeability testing, and $100 \mathrm{~mm}$ cube specimens for compressive strength testing. The slab specimens contained an electrode array for resistance measurements. Concrete mixing was undertaken in accordance with BS 1881: part BS1881-125 (1986) and the fresh concrete was assessed for slump test according to BS-EN:12350-2 (2000) and air content (BS-EN:12350-7, 2000). Concrete of cubes was compacted in moulds in two layers using a vibrating table. The blocks were cast on their sides, and the poker was used to compact concrete. The specimens were covered with wet hessian and placed in a constant temperature room $\left(18 \pm 2^{\circ} \mathrm{C}\right)$.

All specimens were de-moulded after 1 day and placed in a temperature controlled water bath $\left(20 \pm 1^{\circ} \mathrm{C}\right)$. Cube specimens were removed after 28 days and 56 days and tested for compressive strength (BS-EN:12390-3, 2009). Fresh properties and compressive strength values for each concrete are summarised in Table 1.

The slabs were removed from the water bath after 3 days, wrapped in polythene sheet and relocated to a constant temperature room $\left(20 \pm 2^{\circ} \mathrm{C}\right)$ until the age of 90 days to remove any influence of hydration on subsequent test results.

\subsection{Test methods}

\subsubsection{High pressure water permeability test}

Figure 1 shows the high pressure water permeability test instrument. The test head was clamped on a specimen and was connected with an air compressor that was used to pressurise the testing system. During measurements, the pressure applied was maintained at 7 bar by advancing the piston of the cylinder. The volume of water within the cylinder was recorded every minute. Each measurement took $120 \mathrm{~min}$ and the details of the test instrument and procedures are given in the previous study (Yang et al., 2015).

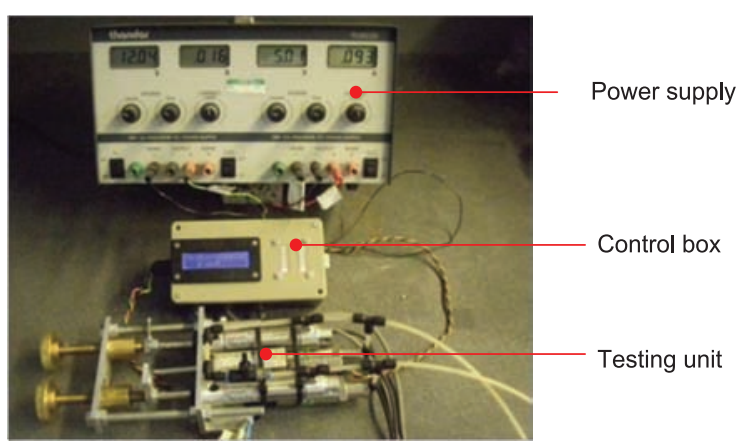

Figure 1. The test set-up of the new water permeability test.

\subsubsection{Vacuum saturation technique}

Figure 2 illustrates the whole test arrangements. Three saturation heads were connected in parallel and clamped on the concrete surface allowing the saturation to be simultaneously carried out at different locations. The vacuum pressure was controlled by a regulator, and a vacuum pressure gage was used to monitor changes of vacuum level in the chamber. 


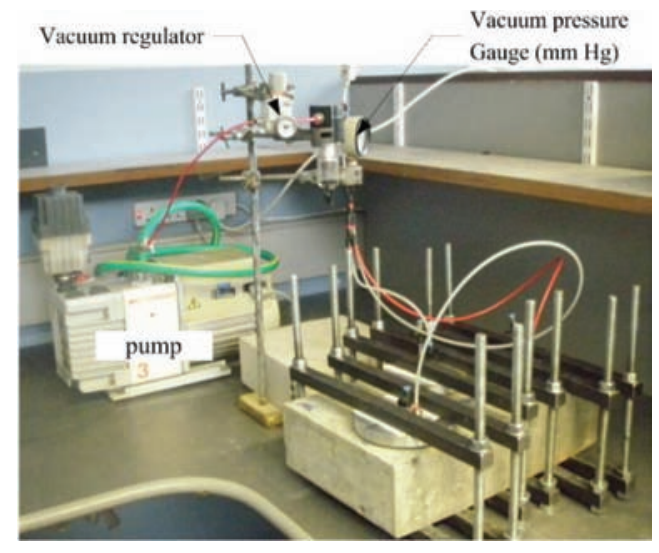

Figure 2. Overall view of the vacuum saturation set-up.

After setting up the vacuum saturation system, the vacuum pump was switched on, and the vacuum pressure was adjusted to the desired level through the regulator. The pressure level was monitored by the gage and adjustments were made, if necessary. By the end of specified periods, water was admitted into the chamber. After filling the saturation heads, vacuum was released, and the specimen was left for another $40 \mathrm{~h}$. Then, the new water permeability tests were carried out.

\section{RESULTS AND DISCUSSION}

\subsection{Assessment of the possibility to achieve} "steady-state" after vacuum saturation

Two vacuum levels and two durations were applied and the levels for both parameters are given Table 2 . The water permeability measurement was carried out after vacuum saturation, and five replicates were carried out for each combination of saturation regime. The concrete tested was MF, and the diameter of the saturation area was $75 \mathrm{~mm}$.

Table 2. Concrete mix proportions and general properties.

\begin{tabular}{lll}
\hline & \multicolumn{2}{c}{ Level } \\
\cline { 2 - 3 } \multicolumn{1}{c}{ Factor } & \multicolumn{1}{c}{+} & - \\
\hline Vacuum pressure & $1(240 \mathrm{~mm} \mathrm{Hg})$ & $-1(40 \mathrm{~mm} \mathrm{Hg})$ \\
Duration & $1(6 \mathrm{~h})$ & $-1(3 \mathrm{~h})$ \\
\hline
\end{tabular}

Figure 3 shows the water flow data after the different vacuum saturation regimes. The behaviour of the water flow was examined before further interpretation, as the new water permeability test is based on the steady-state flow. The duration to reach a "steadystate" flow rate was checked (Yang et al., 2015). It is evident that the relationships between the volume and time are non-linear, especially for the initial period and the outliers can be easily identified in the plots due to unusually high flow rates.

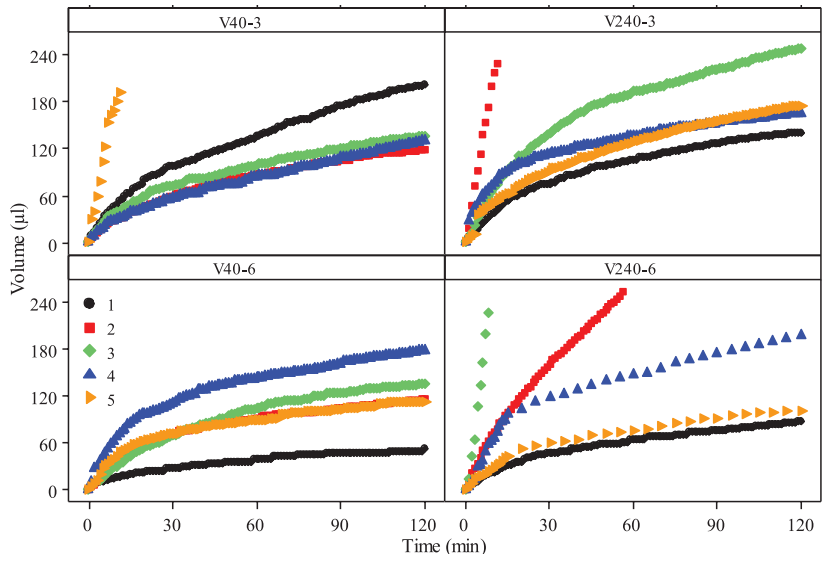

Figure 3. Test data of the water permeability tests after vacuum saturation. Note: V240-3 refers to vacuum saturation at $240 \mathrm{~mm} \mathrm{Hg}$ for $3 \mathrm{~h}$; V240-6 refers to vacuum saturation $240 \mathrm{~mm} \mathrm{Hg}$ for $6 \mathrm{~h}$; V40-3 refers to vacuum saturation $40 \mathrm{~mm} \mathrm{Hg}$ for $3 \mathrm{~h}$; V40-6 refers to vacuum saturation at $40 \mathrm{~mm} \mathrm{Hg}$ for $6 \mathrm{~h}$.
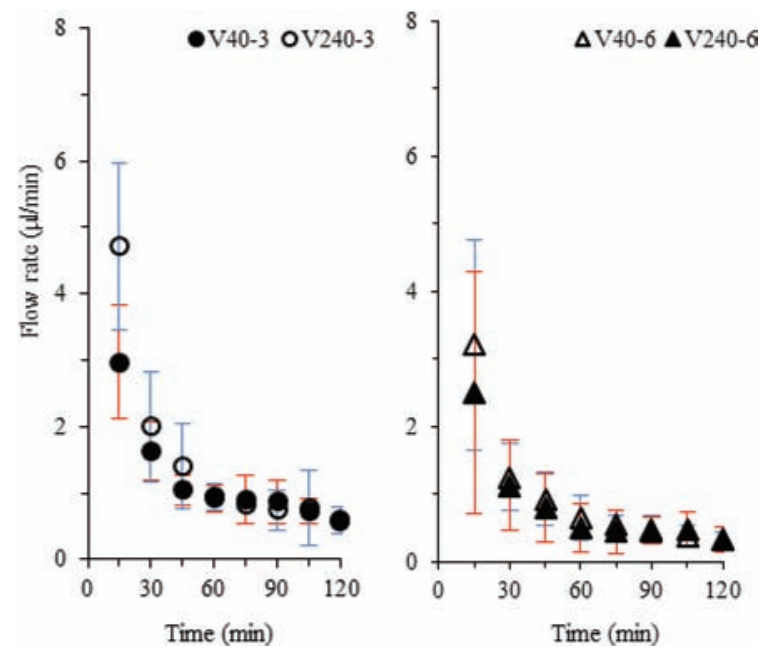

Figure 4. The relationship between flow rates and time.

The flow rates at different times were estimated using the regression analysis between the volume of the water flow and the time. Figure 4 shows the relationship between the flow rates and test duration, and the error bar refers to the standard deviation of the flow rates. The results indicate that the flow rates decrease with increasing time and the standard deviations are not constant, but relied on the magnitude of flow rates. Moreover, the flow rates seem to stabilise after $45 \mathrm{~min}$ as the variations in the flow rates are comparatively small. As such, the flow rates were estimated based on regression analysis of the data after $60 \mathrm{~min}$.

\subsection{Comparison of the flow rates with that after incremental immersion}

The effectiveness of vacuum saturation and ponding were examined to identify if the effect of moisture 
has been eliminated. The flow rates after both preconditioning regimes were compared with that after incremental immersion (two incremental immersion periods, 6 and 10 days, were also applied to study if the duration of immersion has a significant effect). Cross-comparison of pairs of treatment means was applied using the least significant difference (LSD) (Montgomery, 1996).

Table 3 summarises the results of LSD. Note that the comparison between flow rates after incremental immersion for 6 and 10 days does not show any significant difference. More importantly, one vacuum saturation regime $(40 \mathrm{~mm} \mathrm{Hg}, 6 \mathrm{~h})$ gives similar flow rates to incremental immersion. It suggests that vacuum saturation is one possible approach to remove moisture influences on the water permeability test, whereas ponding for $48 \mathrm{~h}$ is non-sufficient. Furthermore, not all the vacuum saturation regimes give satisfactory results, but only the lower vacuum pressure $(40 \mathrm{~mm} \mathrm{Hg})$ with the longer duration $(6 \mathrm{~h})$ is workable.

Table 3. Summary of cross-comparison of the flow rates determined from the new water permeability tests after different preconditioning regimes.

\begin{tabular}{lcrrrr}
\hline $\begin{array}{l}\text { Saturation } \\
\text { method }\end{array}$ & Treatment & $\begin{array}{c}\text { Mean } \\
\text { difference }\end{array}$ & Error & t-Statistic & $P$-value \\
\hline V240-3 & 1 vs. 2 & 0.100 & 0.107 & 0.929 & 0.3620 \\
(NO. 1) & 1 vs. 3 & -0.042 & 0.107 & -0.389 & 0.7002 \\
& 1 vs. 4 & 0.234 & 0.102 & 2.303 & 0.0299 \\
& 1 vs. 5 & 0.327 & 0.102 & 3.212 & 0.0036 \\
& 1 vs. 6 & 0.352 & 0.102 & 3.458 & 0.0020 \\
V246-6 & 2 vs. 3 & -0.141 & 0.107 & -1.318 & 0.1994 \\
(NO. 2) & 2 vs. 4 & 0.135 & 0.102 & 1.324 & 0.1975 \\
& 2 vs. 5 & 0.227 & 0.102 & 2.233 & 0.0347 \\
& 2 vs. 6 & 0.252 & 0.102 & 2.479 & 0.0203 \\
V40-3 & 3 vs. 4 & 0.276 & 0.102 & 2.713 & 0.0119 \\
(NO.3) & 3 vs. 5 & 0.368 & 0.102 & 3.622 & 0.0013 \\
& 3 vs. 6 & 0.393 & 0.102 & 3.869 & 0.0007 \\
V40-6 & 4 vs. 5 & 0.092 & 0.096 & 0.964 & 0.3441 \\
(NO.4) & 4 vs. 6 & 0.117 & 0.096 & 1.226 & 0.2318 \\
IM-6 & 5 vs. 6 & 0.025 & 0.096 & 0.261 & 0.7961 \\
(NO.5) & & & & & \\
\hline
\end{tabular}

\subsection{Effectiveness of the proposed vacuum saturation regime for $P C$ and PFA}

The other two HPCs (PC and PFA) were tested to verify the proposed vacuum saturation regime. The samples were sealed cured for 90 days, and the water permeability tests were carried out after vacuum saturation and incremental immersion, the results are plotted in Figure 5. The flow rates of incremental immersion and vacuum saturation were compared by t-tests according to ISO-3301 (1975). It is found that no statistically significant difference can be seen between flow rates between two precondition regimes. As such, the proposed vacuum saturation procedure is sufficient to achieve the values similar to incremental immersion.

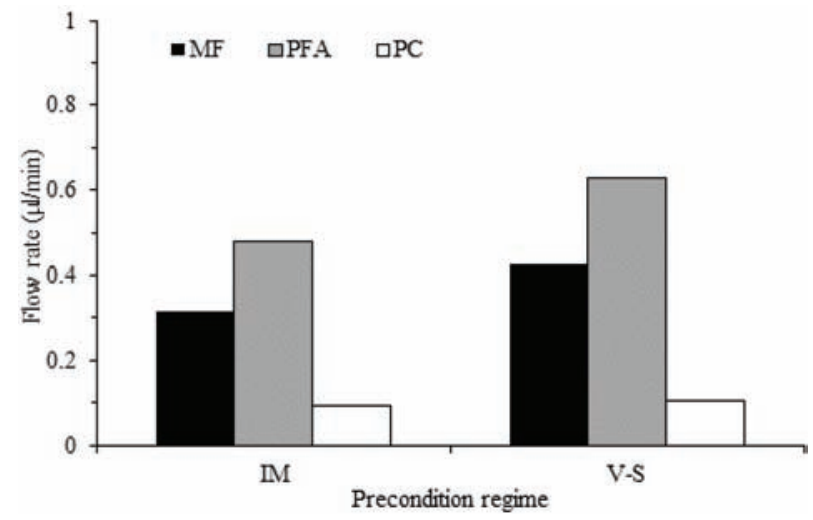

Figure 5. Comparison of flow rates after saturating by incremental immersion and vacuum saturation for three different concrete mixes.

Based on above analysis, it can be concluded that the proposed vacuum saturation regime is effective to remove the moisture influence. However, the measurements were performed under a specific initial condition. The moisture content of concretes was quite high, as the samples were not exposed to any drying conditions. Not many structures in service can meet this requirement; and hence, further experiments of the proposed vacuum saturation regime were carried out.

\subsection{Effectiveness of vacuum saturation after oven drying}

The effectiveness of vacuum saturation was further assessed using concrete, which was under the "dry" condition. To achieve this, the samples were dried in an oven at $40^{\circ} \mathrm{C}$ for 7 days and cooled in a constant temperature room $\left(20^{\circ} \mathrm{C}\right)$ for 1 day. This drying regime was chosen as most free moisture in the coarse pores can be removed in this regime (Yang et al., 2014). After applying vacuum saturation, the water permeability tests were carried out. The diameter of vacuum saturation area was $75 \mathrm{~mm}$.

Figure 6 compares the flow rates after incremental immersion and vacuum saturation. Evidently, all of the flow rates after vacuum saturation are much greater than that after incremental immersion. The relative change compared with incremental immersion is 4-6 for MF and PFA, while more than 40 times for $\mathrm{PC}$ that has the greatest volume among the three concretes, contrary to the trend obtained after incremental immersion. Such a significant change in flow rates must be due to specific causes. The above 


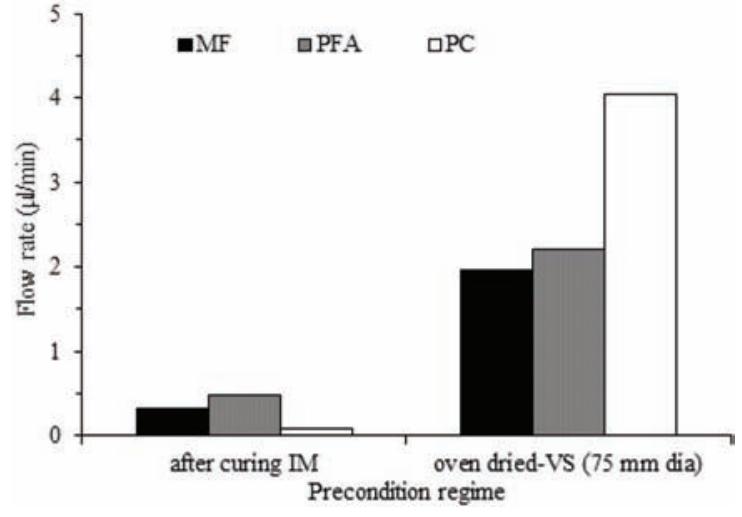

Figure 6. Flow rates after incremental immersion and vacuum saturation.

observations imply that the proposed saturation regime is questionable to use under the "dry" condition.

To clearly inspect the flow patterns, water flow was simulated by the model as the previous work (Yang et al., 2015). Figure 7 shows the relative flow rates at different locations, where all flow rates were normalised to the central point on the test surface. It reveals that the flow rate on the surface increases with increasing distance to the line of symmetry and reaches maximum value at $25 \mathrm{~mm}$, around 2.6 times higher than that at the centre point. At the deeper levels, the relative flow rates are comparatively constant and at 30 and $40 \mathrm{~mm}$ the flow rates are $<0.5$. The direct measurement of flow rates at different depths carried out by Whiting and Cady (1992) has also shown that the flow rate is negligible beyond $1 \mathrm{in}$. (25.4 mm). A similar finding was also reported by Guth and Zia (2001).

The other notable feature of Figure 7 is that the flow rates at different levels beyond $70 \mathrm{~mm}$ (distance to the symmetric axis) are close to 0 . The diameter

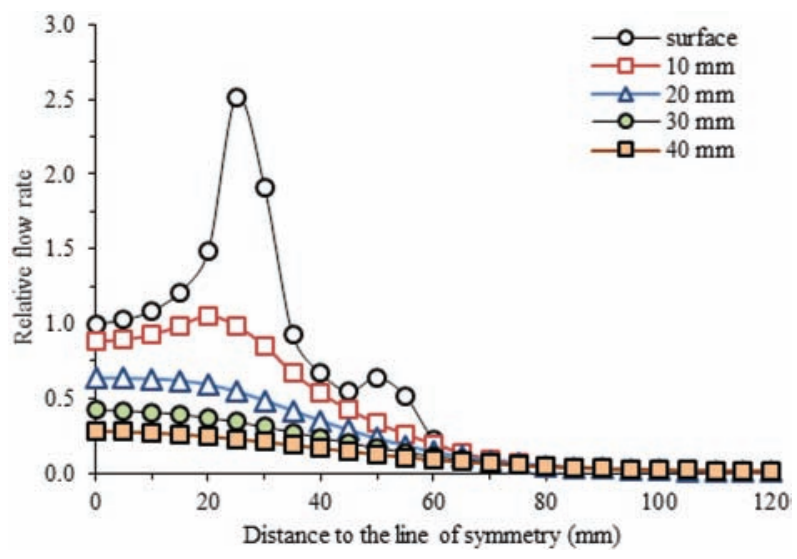

Figure 7. The relative flow rates at different locations determined from the saturated model. of saturation area is $75 \mathrm{~mm}$ which means only $37.5 \mathrm{~mm}$ around the symmetric axis is saturated. In the unsaturated region, water flows faster due to the compressibility of air and water would fill unsaturated pores. Pores can be saturated by the inflow water eventually, but as Scherer (2008) has highlighted, this process would last for a very long period, meaning that a longer test duration is not suitable to solve this problem, especially for field application.

One way to solve this problem is to increase the saturation area. Considering the model features and the available size of testing surface $(410 \mathrm{~mm} \times 250 \mathrm{~mm})$, a larger saturation area (a diameter of 180 and $20 \mathrm{~mm}$ seal) was selected. The vacuum saturation was applied by using the new head, while the intensity of vacuum and the duration were not changed. An overall comparison was made for different conditions displayed in Figure 8. The sign of "VS" means vacuum saturation, while "AC" and "OD" refer to the initial condition of specimens: after curing $(A C)$ and after oven dried (OD).

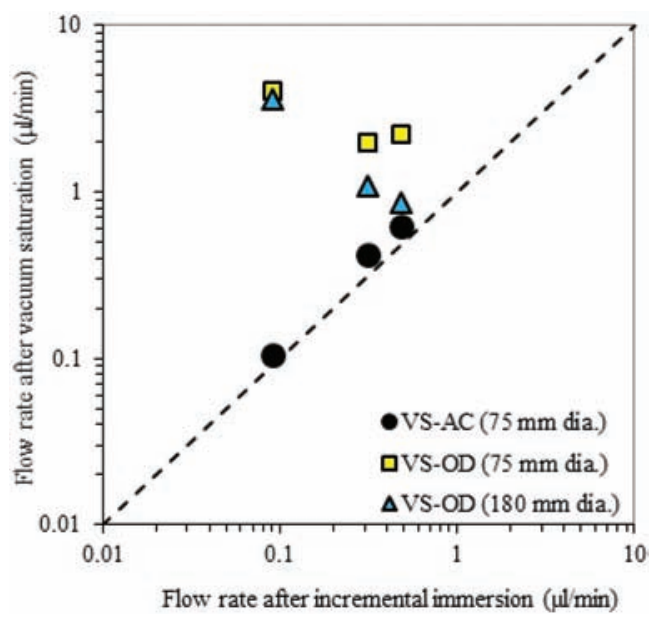

Figure 8. Comparison of flow rates after incremental immersion and vacuum saturation.

Two notable features can be found. First, the influences of moisture cannot be entirely removed, as the flow rates are higher than these after incremental immersion. More importantly, different trends were found for the three concretes. The largest difference in flow rates between vacuum saturation and incremental immersion was found for PC, while the flow rates of PFA under VS-OD (180 mm diameter) were very close to the equal line. This means that the concrete with the lowest permeability is insensitive to the saturation regime, which is the reason for the "wrong" trend under the "oven dried" condition.

Another significant influencing factor is the initial condition, which directly determines the effect of vacuum saturation. Only under certain conditions (in 
this case after sealed curing), the vacuum saturation method used in this study can reach similar trend to what was obtained after incremental immersion. After oven drying, an opposite trend was seen. In other words, the proposed preconditioning regime should be used with extreme care.

\section{CONCLUSION}

In this study, the effect of ponding and vacuum saturation on the new water permeability test was assessed. It is found that the vacuum saturation gives statistically similar results compared with results after incremental immersion when the moisture content is high. However, not all vacuum preconditioning regimes are effective, but only the low level of vacuum $(40 \mathrm{~mm} \mathrm{Hg})$ and the long duration $(6 \mathrm{~h})$ is able to achieve this aim. Furthermore, the proposed vacuum saturation regime may generate misleading results, if the initial moisture content of tested concrete is low.

Furthermore, the permeability of HPCs is a complicated function of many factors, especially sensitive to the construction practice. Therefore, direct measurements of permeability on site are highly recommended, and the new test method could be a potential technique for this purpose.

\section{ACKNOWLEDGMENTS}

The work was carried out at Queen's University Belfast and facilities provided by the School of Planning, Architecture and Civil Engineering at Queen's are gratefully acknowledged. The authors also wish to express their gratitude and sincere appreciation to the financial support provided by the EPSRC, NSFC (NO. 51408078), and Central University Grant (NO. 106112015CDJXY130012).

\section{REFERENCES}

Adams, A. E. (1986). Development and application of the CLAM for measuring concrete permeability (PhD). Queen's University Belfast.

Basheer, P. A. M. (1991). 'CLAM' permeability tests for assessing the durability of concrete (PhD). Queen's University Belfast.

Basheer, P. A. M. (2001). Permeation analysis. In V. S. Ramachandran \& J. J. Beaudoin (Eds.), Handbook of analytical techniques in concrete science and technology: Principles, techniques and applications (pp. 658-727). Noyes Publications.

BS1881-125. (1986). Methods for mixing and sampling fresh concrete in the laboratory. BSI, p. 10.
BS-EN:12350-2. (2000). Testing fresh concrete-2: Slump test. London, England: BSI, p. 8.

BS-EN:12350-7. (2000). Testing fresh concrete-7: Air content. Pressure methods. London, England: BSI, p. 20.

BS-EN:12390-3. (2009). Testing hardened concrete-3: Compressive strength of test specimens. BSI, p. 22.

BS-EN:13263-1. (2009). Silica fume for concrete. Definitions, requirements and conformity criteria. BSI, p. 28.

BS-EN:197-1. (2000). Cement. Composition, specifications and conformity criteria for common cements. BSI, p. 52.

BS-EN:450. (2005). Fly ash for concrete - Part 1: Definition, specifications and conformity criteria. BSI, p. 36.

Bungey, J., Millard, S. G., \& Grantham, M. (2006). Testing of concrete in structures. Spon Press.

Elahi, A., Basheer, P. A. M., Nanukuttan, S. V., \& Khan, Q. U. Z. (2010). Mechanical and durability properties of high performance concretes containing supplementary cementitious materials. Construction and Building Materials, 24(3), 292-299.

Figg, J. W. (1973). Methods of measuring the air and water permeability of concrete. Magazine of Concrete Research, 25, 213-219.

Guth, D. L., \& Zia, P. (2001). Evaluation of new air permeability test device for concrete. $\mathrm{ACl}$ Materials Journal, 98, 44-51.

ISO-3301. (1975). Statistical interpretation of data. Part: 6 comparison of two means in the case of paired observations. ISO, p. 14.

Meletiou, C. A., Tia, M., \& Bloomquist, D. (1992). Development of a field permeability test apparatus and method for concrete. ACl Materials Journal, 89, 83-89.

Montgomery, D. C. (1996). Design and analysis of experiments. John Wiley \& Sons.

Parrott, L. J., \& Hong, C. Z. (1991). Some factors influencing air permeation measurements in cover concrete. Materials and Structures, 24, 403-408.

Russell, D. P. (1999). Influence of environmental conditions and material properties on carbonation in concrete (PhD). Queen's University Belfast.

Scherer, G. W. (2008). Poromechanics analysis of a flow-through permeameter with entrapped air. Cement and Concrete Research, 38(3), 368-378.

Torrent, R. T. (1992). A two-chamber vacuum cell for measuring the coefficient of permeability to air of the concrete cover on site. Materials and Structures, 25, 358-365.

Whiting, D. (1981). Rapid determination of the chloride. Permeability of concrete. FHWA/RD81/119, Federal Highway Administration: 173. 
Whiting, D., and Cady, P. D. (1992). Condition evaluation of concrete bridges relative to reinforcement corrosion. Washington, DC: Strategic Highway Research Program. Volume 7: Method for Field Measurement of Concrete Permeability (SAF): 93.

Yang, K., Basheer, P. A. M., Bai, Y., Magee, B. J., \& Long, A. E. (2014). Development of a new in situ test method to measure the air permeability of high performance concretes. NDT \& E International, $64,30-40$.
Yang, K., Basheer, P. A. M., Bai, Y., Magee, B. J., \& Long, A. E. (2015). Assessment of the effectiveness of the guard ring in obtaining a unidirectional flow in an in situ water permeability test. Materials and Structures, 48(1), 167-183.

Yang, K., Basheer, P. A. M., Magee, B., Bai, Y., \& Long, A. E. (2015). Repeatability and reliability of new air and water permeability tests for assessing the durability of high-performance concretes. Journal of Materials in Civil Engineering, 27(12). 